\title{
Bridging the social divide? reflections on current Dutch neighbourhood policy
}

\author{
Wouter P. C. van Gent · Sako Musterd · Wim J. M. Ostendorf
}

Received: 19 March 2008/Accepted: 7 April 2009/Published online: 24 April 2009

(C) The Author(s) 2009. This article is published with open access at Springerlink.com

\begin{abstract}
Current Dutch urban policy has opted for a focused approach to solve urban social problems. The Minister of 'Housing, Neighbourhoods and Integration' aims at tackling social deprivation and liveability problems in a limited number of neighbourhoods. Several assumptions underpin the policy ambitions: e.g., a strong interrelationship between social deprivation and liveability; a clear social and spatial divide in Dutch society; and extra negative effects of problem accumulation. In this paper, these assumptions are tested. It is concluded that the two types of problems are in fact unrelated; targeting a limited number of neighbourhoods does not effectively address social deprivation. Furthermore, there is yet insufficient research to support the idea that there would be extra negative effects associated with an accumulation of social deprivation and liveability problems.
\end{abstract}

Keywords 40 Neighbourhoods programme - Area-based initiatives · Evidence-based policies · Neighbourhood regeneration · The Netherlands · Urban policy

\section{Introduction}

The Netherlands is a 'policy-dense' country, and this is particularly true for the field of urban policies. In the last decade Dutch urban policy, in three editions of the big city policy (BCP), has set out to deal with the economic, social and physical issues in an integrated

W. P. C. van Gent $(\bowtie)$ - S. Musterd · W. J. M. Ostendorf

Department of Geography, Planning and International Development Studies, Universiteit van Amsterdam, Nieuwe Prinsengracht 130, 1018 VZ Amsterdam, The Netherlands e-mail: W.P.C.vanGent@uva.nl

S. Musterd

e-mail: S.Musterd@uva.nl

W. J. M. Ostendorf

e-mail: W.J.M.Ostendorf@uva.nl 
and area-based way. Simultaneously, the policy aims to bring resources and responsibilities to decentralized levels of government. The underlying objective was initially to create 'the comprehensive city' and in later editions to create a 'powerful city' or a 'safe' and 'liveable' city. All BCP policies were aimed at reducing the number of persons with inadequate education levels, intended to reduce integration problems, diminish crime and unsafe environments, tackle high unemployment rates, reduce out-migration of the dwindling middle class, and support economic vitality (Musterd and Ostendorf 2008). In these respects, Dutch urban policies connect to a common social exclusion policy discourse in Western Europe (see Atkinson 2000; Andersen 2003; De Decker et al. 2003). Furthermore, the BCP intended to remove dilapidated housing and commercial buildings, and to overcome inadequate infrastructures and poor accessibility. The notion behind such approaches was that problems accumulate and become concentrated in specific districts and that these issues are all related to each other. Indeed, the interconnectedness of several urban issues was a main driver behind the launching of large-scale, integrated area-based interventions to urban problems. Like other area-based initiatives in Western Europe, Dutch interventions often include extensive urban renewal at the neighbourhood level to restructure the housing market (Belmessous et al. 2005; Cole and Etherington 2005).

The recent 40 neighbourhoods programme is an extension of earlier programmes which sought to accelerate the process of urban renewal and housing market restructuring in a number of problem neighbourhoods. However, because of its pronounced social agenda, the 40 neighbourhoods programme can be characterised as an addition to the running BCP. The programme is named after its strategy to target the 40 worst problem areas, which were selected on grounds of empirical evidence.

The purpose of this paper is to evaluate the choices in and the operationalisation of the 40 neighbourhoods programme and to confront the stated intentions with empirical findings. The main question of this paper is: How well is the actual neighbourhoodtargeted policy in The Netherlands connected to its stated intentions, particularly those related to social issues? Our analysis is based on the first steps of the policy cycle: the conception of the problems and the social phenomena that need to be altered. Please note, we do not evaluate the programme ex post. Instead, by critically examining the envisioned stated social ambitions and intentions, the assumptions based on that, and the selection of neighbourhoods to be targeted, we will gauge its effectiveness and limitations a priori.

To analyse any policy programme with a social agenda, it is important to examine the underlying conceptualisation of where, when and how the programme seeks to intervene in the social systems and what the expected outcomes will be (Pawson and Tilley 1997). Unfortunately, these conceptualisations are not always made explicit in urban policies (Rhodes et al. 2005). Statements and policy documents may reveal some intentions. However, in addition to statements, the intention and objectives of intervention are also reflected in the conceptualisation of evidence. Ideally, in the case of an area-based programme such as the 40 Neighbourhoods Programme, the selection indicators should reflect the objectives of the programme, as they determine which neighbourhoods will be subjected to intervention. The conceptualisation of evidence should reflect the agendas and goals of the policy, and ultimately affect the actions taken (Solesbury 2002). However, we should also note that evidence is not neutral but connected to issues of power, participation and inequality (Parsons 2002; Davoudi 2006). The notion that policy orientation is contextual and influenced by politics is certainly not new (Laswell in Parsons 2002). Nonetheless, the use of evidence in the form of 'objective indicators' in the 40 neighbourhoods programme seems to be an attempt to defy political haggling. 


\section{Neighbourhoods programme: urban policy with social ambitions}

In 2007, the Dutch centre-left coalition government created a new ministerial post within the Ministry of Housing and Spatial Planning to oversee the political project to transform 'problem neighborhoods' into 'vigorous' and 'socially strong' neighbourhoods. According to official correspondence between the minister and Parliament, ${ }^{1}$ there is a severe social problem in Dutch society which relates to the accumulation of 'severe liveability problems' in certain neighbourhoods. More specifically, these liveability problems are related to the existence of 'physical and socio-economic deprivation and problems'. The nature of these problems will be explored below. However, it is clear that the accumulation of problems in certain areas is assumed to create an increasing gap between the poor neighbourhoods and the rest of society. The policy programme is designed to counter the threat of a divide that will disconnect the poor from the rest of society and drive them towards social exclusion. So, the strategic issue at hand is the danger of the development of 'parallel societies'.

Although urban policies originally involve the transformation of places, the 40 neighbourhoods programme strongly emphasises the social issues of its residents and its social approach alongside physical interventions. As the responsible minister commented, '[it is] an approach which heavily invests in people who live in the neighbourhood, because people define the neighbourhood' (Vogelaar 2008, July 10).

So, the Programme seems to tackle two issues: social-economic deprivation among individuals and liveability issues. As said, liveability issues include forms of anti-social behaviour, but also traffic nuisance, safety, pollution, and housing and neighbourhood satisfaction. The assumption seems to be that there are localised accumulations of mutually reinforcing social processes and physical deterioration that create liveability problems and social deprivation. These accumulations can be identified in a clear selection of Dutch neighbourhoods. To produce 'liveable' neighbourhoods and social inclusion, the Programme employs a range of integrated measures. A significant component will likely be physical restructuring and urban renewal. Other interventions relate to employment, education, safety, social integration and housing. Thereby, interventions are both locale- and people-based.

The neighbourhoods within the 40 chosen problem areas will be regenerated by integrated actions involving the state, municipalities, social welfare organisations, residents and-mainly-local housing associations. Although housing associations have been active in urban renewal for many decades, housing associations are a relatively new actor in social activities and objectives of urban policies (see Boelhouwer 2007). The associations will contribute to a fund from which most of the investments needed will be drawn. Local governments also are expected to invest substantial amounts of money in these neighbourhoods. Although most of the fund is expected to be used for physical purposes, parts of it may and actually are expected to be used for social purposes as well. Social activities include integration programmes, education programmes, and intensive monitoring and support of poor 'multi-problem families'. In addition, in the 2008 government budget new funds have been allocated to avoid displacement effects. This underlines the importance of people alongside place.

\footnotetext{
${ }^{1}$ Letters from the Ministry to Parliament on 22 March and 24 April 2007.
} 


\section{Problems and indicators}

Atkinson et al. (2002) state that social indicators should reflect the essence of the problem and have a clear and generally accepted normative meaning. The policymakers of the 40 neighbourhoods programme pride themselves on the selection of the 40 'worst' neighbourhoods based on 18 'objective indicators'. However, the selection was also based on consultations with municipalities. This political component seems to contradict the former claim of 'objective' selection. We pay further attention to this contradiction below.

In the official selection, the Ministry defined two types of indicators: deprivation indicators, which reflect situations of 'lagging behind'; and problem indicators, which reflect the opinions of the residents. Furthermore, the holistic and integrated character of the Programme is reflected in a second distinction in the indicators: social (economic) and physical. Also, all indicators are static and fail to represent any change of the neighbourhoods.

The socio-economic indicators consist of income, education, and employment. In addition, the social dimension is complemented by the opinions of the residents on liveability issues. However, while the socio-economic indicators seem to connect reasonably well to the wish for social inclusion and liveable neighbourhoods, the physical indicators are less straightforward.

Even though physical issues are mentioned in the official communications, the exact nature of these issues remains unclear. Because of the liveability objective, we assume that these issues refer to physical deterioration of buildings or individual dwellings. However, the technical quality of the Dutch housing stock is generally good and there is hardly any physical deterioration (Van der Schaar 2006). When examining the 'physical deprivation' indicators it is clear that the concern is not technical in nature. The three indicators that were used are the share of old (pre-1970) dwellings, of small dwellings, and of cheap dwellings. None of these refer directly to the quality of the housing. There is no obvious relation between small and cheap housing and physical deterioration or substandard housing; in fact, substantial parts of the most affluent housing are pre-1970. Moreover, small housing may serve specific housing needs (the elderly, students) or may be highly desired at certain attractive locations (in or around city centres). Furthermore, good-quality inexpensive housing serves the needs and demand of the less well off, who are not necessarily in need of any social assistance. In sum, these indicators are unclear concerning the problems and the need for policy intervention they represent.

Moreover, the data used for the 'cheap housing' indicator concern the share of social rented dwellings per area. This suggests that there is a relationship between deterioration or deprivation and social rented housing. While there are indications that the share of lowincome households within the social rented sector is increasing (Van Kempen and Priemus 2002), the current size and quality of the social rented sector in The Netherlands (about $35 \%$ of the total housing stock, and around $50 \%$ in cities) does not (yet) warrant any claims of 'residualisation' of the kind that was experienced in the UK since the 1980s (cf. Forrest and Murie 1990). Size and quality means that there is a substantial share of the middle class in the social rented sector, which 'muffles' the relationship between income and tenure. Hence, the share of social housing does not necessarily indicate a source or cause of deprivation, deterioration or problems, and is not valid in this respect. We may speculate that the use of the indicator is perhaps best explained by the involvement of the housing associations in the Programme. As the housing associations are the owners and managers of social-rented housing, a logical prerequisite for their local involvement is a substantial presence of social-rented housing in a targeted area. However, this is at variance with the 'objective selection' of neighbourhoods. 


\section{Testing three fundamental assumptions}

The stated intentions and used indicators seem to indicate that the Programme has three fundamental assumptions that form the basis for the rationale of changing two social processes in select neighbourhoods:

(a) liveability issues and social-economic deprivation are related phenomena,

(b) which accumulate in 40 neighbourhoods,

(c) and which create a social division in Dutch society that manifests itself in a division of neighbourhoods.

To test these policy assumptions, we have attempted to reconstruct the dataset used by the Ministry. However, we have remained critical of the variables and only included indicators that reflect the socio-economic situation and liveability of neighbourhoods. Consequently, we have done away with all the indicators that we deem invalid or unreliable to test. The invalid variables are the 'physical deprivation' indicators discussed above (old, small dwellings, and cheap dwellings). In addition, we have also excluded the Programme indicator 'propensity to move'. Although moving may be related to the social situation in the neighbourhood, it may also reflect the phase in the housing career. For example, young households tend to move more than elderly ones; therefore, neighbourhoods with relatively many young households will show high residential mobility; usually this is not an indication of problems. The fifth excluded indicator is level of education. Although this is a valid indicator for deprivation, the data was based on a telephone survey, which asked respondents to gauge the average level of education of their street. This requires respondents to know their neighbours, objectively assess an average level and relate this to national averages. Because such an assessment will most likely be heavily biased, we deem this data unreliable (see Van Gent et al. 2007).

So, we are left with a set of indicators that reflect social deprivation and liveability issues on a neighbourhood level. ${ }^{2}$ The six (composed) indicators are:

Social deprivation ${ }^{3}$

- Average disposable income per household

- Employment rates,

\section{Liveability $^{4}$}

- Physical Nuisance Index based on 4 indicators (noise nuisance, pollution, traffic nuisance, traffic safety),

- Social Nuisance Index based on five indicators $(2 \times$ vandalism, $2 \times$ social nuisance, insecurity),

- Dwelling dissatisfaction,

- Environment dissatisfaction

\footnotetext{
2 The Programme selection used data on a 4-digit postcode level. The neighbourhoods of our analysis, however, are neighbourhood-based areal units based on municipal and CBS delineation. Like the Programme, individual data from WoON survey was aggregated to a 4-digit postcode level. In our analysis this data was projected on the geographically smaller CBS areas.

${ }^{3}$ Although valid, we have excluded the education indicator due to reliability issues. Source of data is CBS 2004.

${ }^{4}$ Source of data is WoON 2006.
} 
In order to test whether these variables all correlate strongly and to be able to test the assumption that they are part of one single dimension, we performed a principal components analysis (PCA). Basically, this is a data reduction tool aimed to discover the smallest number of dimensions that are covered by the variables included in the analysis.

The PCA resulted in two independent components that together account for $64 \%$ of the variance. The rotated component matrix is shown in Table 1. The PCA's first component clearly represents the liveability indicators, while the second component represents the social deprivation indicators. This means that, based on the indicators used by the Ministry, the level of liveability issues and the level of social deprivation in a neighbourhood are essentially unrelated phenomena in The Netherlands. Hence, the first policy assumption appears to be false. Yet, social economic deprivation and liveability issues can both be present in selected areas.

Like British evidence-based urban policies, the Programme operationalises the threshold of issues and problems as neighbourhood scores that are twice the standard deviation below the national average. The aim is to reduce the distance between the scores of the selected 'most deprived' neighbourhoods and the national average.

Figure 1 shows the scores of the two components of our PCA set out against each other in a scatter plot. Like the 40 neighbourhoods programme, we define 'problematic' neighbourhoods as cases with component scores that deviate at least two standard deviations from the national average.

When examining Figure 1, it becomes immediately clear that liveability issues and social deprivation are generally unrelated; that is to say, based on the indicators used for the selection of the neighbourhoods. Moreover, based on the indicators used, there is no reason to suggest that there is a division in Dutch society which manifests itself spatially. Rather, we see that there is a group of neighbourhoods with a large share of unemployed and low-income households and a group of neighbourhoods with liveability problems. A small number of neighbourhoods (28) fall in both categories, showing serious social deprivation as well as serious liveability problems. All of these neighbourhoods fall within the boundaries of 15 of the 40 Programme neighbourhoods (the Ministry is using larger areas). However, even though almost all of the selected neighbourhoods score below average, the official selection does not seem to form a clearly distinguishable group of neighbourhoods that are separated from the rest of society. Moreover, there is no rationale for the government's selection of the remaining 25 neighbourhoods; these are not essentially different from a large number of other neighbourhoods that are not selected. These findings support our statement that also the second and third assumption appear to be false.

The differences between our analysis and the official selection are most likely due to the policymakers' use of indicators that do not seem suitable to detect accumulations of social-

Table 1 Rotated component matrix (Varimax rotation with Kaiser Normalization)

\begin{tabular}{lcr}
\hline & \multicolumn{2}{l}{ Component } \\
\cline { 2 - 3 } & 1 & \multicolumn{2}{l}{2} \\
\hline Average disposable income per household & .099 & .835 \\
Employment rates & -.301 & .637 \\
Physical nuisance index & .850 & .062 \\
Social nuisance index & .884 & -.061 \\
Dwelling dissatisfaction & .585 & -.423 \\
Environment dissatisfaction & .685 & -.383 \\
\hline
\end{tabular}




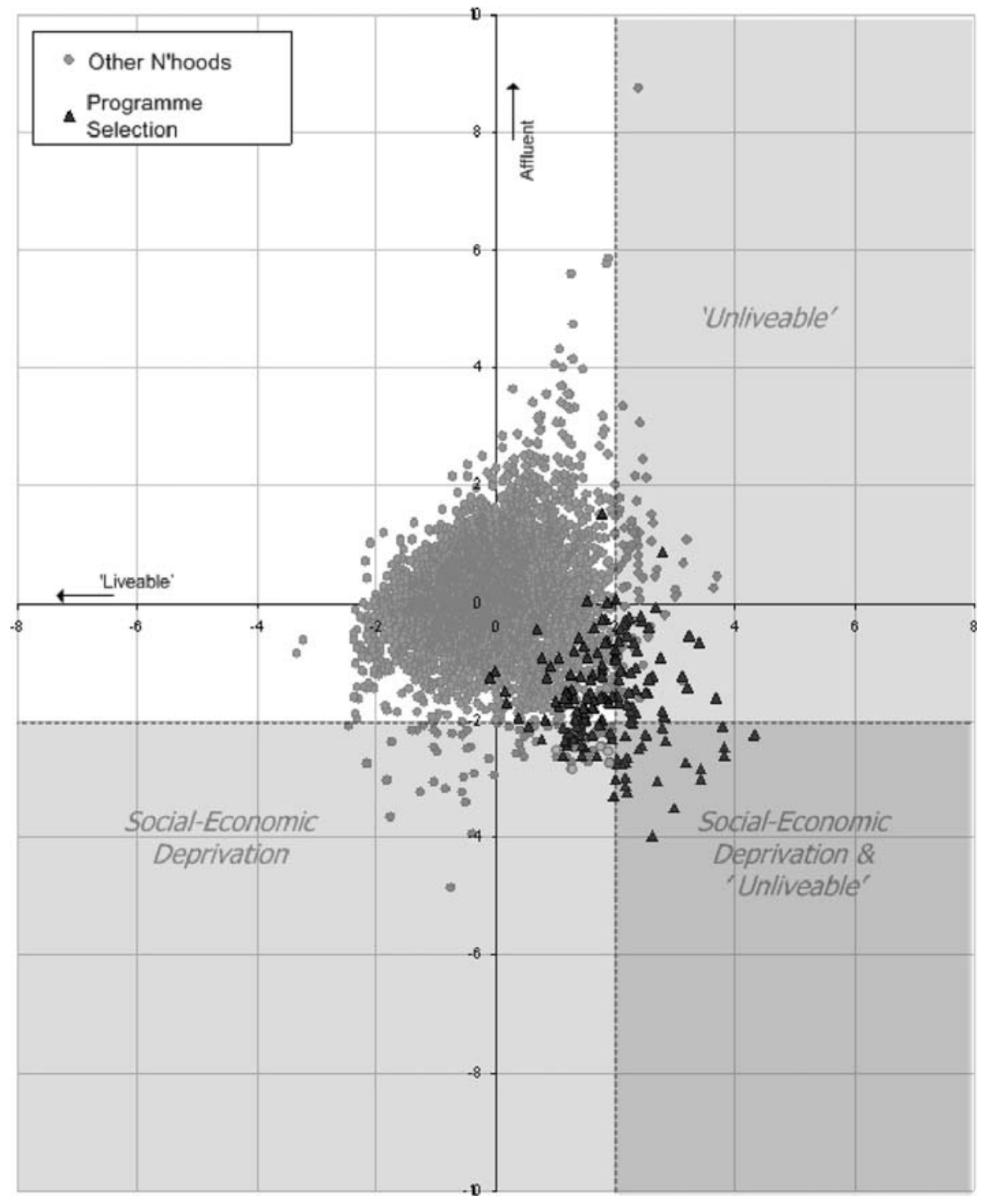

Fig. 1 Component scores plot

economic or liveability problems or are due, perhaps, to the political component in the selection.

Thus, we can find no evidence for the three policy assumptions mentioned above. The stated ambitions have the clear notion that in order to create liveable neighbourhoods and to combat social deprivation, the Programme should target a group of 'worst' neighbourhoods. As we have seen, the official programme selection does not justify the claim of a group of 'worst' neighbourhoods. The majority of the selected areas do not stand out.

Furthermore, as social deprivation and liveability are found to be unrelated, it would be better for any national policy response to treat the phenomena as two separate issues. The 
question then is whether it is prudent or effective to tackle both issues in one area-based programme. One important argument for issuing one programme is the 'accumulation of problems' argument. This implies that separate problems and issues within one area not only stack up, but also reinforce each other. This connects to the idea of neighbourhood effects, for which, however, the existence and causal pathways are not undisputed in the literature (see Galster 2007).

Another possible rationale for giving the neighbourhoods in the lower-right quadrant of Fig. 1 extra policy attention is that in some cases liveability issues related to crime and safety threaten the effective delivery of sectoral public services. While the withdrawal of the state in any type of neighbourhood can have catastrophic results, those areas with a high share of socially excluded persons may be extra vulnerable as there is a lower degree of self-sufficiency. For the Dutch case, both the authors of this paper and the Ministry have no evidence that such a tipping point has been reached in the 'worst' neighbourhoods. However, these scores do warrant closer inspection and further research.

However, referring back to the strategic objective of the Programme-to prevent social division in Dutch society-we contend that this objective is more relevant to social deprivation issues than it is to the unrelated liveability issues. Many of the 'unliveable' neighbourhoods (cases with extreme scores on the liveability component) are in fact populated by affluent households. Moreover, some of the most affluent neighbourhoods in The Netherlands are labelled 'unliveable' largely due to residents' complaints about traffic nuisance.

\section{Discussion: liveability in neighbourhoods and social exclusion in society}

To be clear, we are not arguing that liveability issues should be disregarded by policies like the 40 neighbourhoods programme. On the contrary, there is merit in tackling liveability issues through area-based initiatives on a neighbourhood level (Lawless 2007). In many cases, liveability issues are unique local phenomena that require environmental approaches that are specific to the locale. Social deprivation could be related to local liveability issues, but to test this supposition the used liveability indicators seem to fall short in two ways. First, the used indicators were often related to external factors such as traffic and visitor nuisances. To test relations between social deprivation and liveability, the liveability indicators should have been related to the residents. Second, the liveability indicators are subjective and depend on expectations of residents. Higher-income households generally have higher expectations, as exemplified by the very affluent, yet 'unliveable', neighbourhoods in Fig. 1 (see Parkes et al. 2002). Any future research or policy selection endeavour would do well to overcome these limitations.

Nevertheless, as we can find no relation between liveability issues and social deprivation on a neighbourhood level, it is hard to maintain that liveability issues are related to social division in society on the same level as social deprivation and exclusion. Thus, when tackling social division, the social phenomenon that it should primarily address is social deprivation beyond the neighbourhood scale. The question then is whether the area-based Programme is suitable for closing the 'growing gap' in Dutch society. Before discussing this point, it may be useful to briefly 'illuminate' the gap with some empirical evidence in order to appreciate its width and depth.

In a European study on social exclusion, The Netherlands has one of the lowest rates of cumulative disadvantage and also one of the lowest probabilities of social exclusion (Tsakloglou and Papadopoulos 2002). Furthermore, both in social and ethnic terms, 
segregation levels are moderate compared to other European cities (Musterd 2005) and are not increasing (Musterd and Ostendorf 2007). Moreover, there always seems to be some social mix in Dutch neighbourhoods. Even in the poorest neighbourhoods of each of the three largest cities, the share of middle-income households turns out to be larger than the share of poor households (Pinkster 2006). This implies that the poor are not spatially cut off from middle-class contact, not even in the poorest neighbourhoods. In sum, research findings do not support the notion of a dual society (Musterd and Ostendorf 2007).

Even though the Dutch gap is no abyss, there is social deprivation and exclusion in The Netherlands. So it may be a legitimate aim to intervene in specific areas to deal with social inequalities. However, Table 2 shows the share of low-income workers and people on benefits who live in the selected 40 neighbourhoods compared to the national total. In a best-case scenario the area-based Programme will only reach $8.1 \%$ of people who run the risk of being excluded - a relatively low percentage, which is probably due to the social mix of Dutch neighbourhoods. In Sweden, Andersson also found that only $4.7 \%$ of all poor households were reached in an area-based social exclusion programme (Andersson and Musterd 2005). This inefficiency raises questions about the use of territorial strategies which aim to fight social deprivation through area targeting.

\section{Conclusion}

Dutch policymakers, despite the use of 'objective indicators', are unable to construct a policy which connects to its main objective-reducing the social division in Dutch society and creating liveable neighbourhoods. This is partly due to the Programme's unclear problem definition, a common error in policymaking (Sanderson 2002). For instance, the Programme does not clarify the object of intervention: places or people. Furthermore, the goal of creating liveable neighbourhoods may be at odds with the goal of fighting social deprivation. While neighbourhoods may be improved, the residents may not benefit from the improvement. Moreover, physical restructuring may result in the involuntarily reallocation of households. This means that residents may move away from their network of friends and relatives. By doing so they also move away from those who provide emotional and material support (cf. Goetz 2003). Furthermore, the goals of improving liveability and reducing social-economic deprivation proved to be incompatible in terms of policy strategy. As liveability problems are connected to specific local situations, there is merit in tackling liveability issues in an area-based fashion, but social exclusion and deprivation should be addressed primarily in a sectoral or people-based way. These ambiguities are

Table 2 Deprivation in the 40 programme neighbourhoods

\begin{tabular}{lrrrrr}
\hline & Population & Households & $\begin{array}{l}\text { Low-income } \\
\text { workers }\end{array}$ & $\begin{array}{l}\text { Persons } \\
\text { (aged 15-64) } \\
\text { on benefits }\end{array}$ & $\begin{array}{l}\text { Persons } \\
\text { (aged 15-64) } \\
\text { on unemployment } \\
\text { benefits }\end{array}$ \\
\hline Total NL & $16,257,390$ & $7,049,280$ & $4,278,151$ & $1,768,874$ & 311,400 \\
40 selected n'hoods & 808,090 & 408,900 & 203,939 & 143,407 & 21,900 \\
$\begin{array}{c}\text { \% selected n'hoods } \\
\text { compared to NL }\end{array}$ & 4.9 & 5.8 & 4.8 & 8.1 & 7.0 \\
\hline
\end{tabular}

Source: CBS 2004 
reflected in the indicators and in our analyses. In our case, some of these ambiguities can be explained by three factors: the history of urban policies; the institutional embeddedness; and current European trends.

First, urban policies in The Netherlands in the last 15 years have strongly favoured restructuring of the housing stock as a means to solve physical as well as social problems. This has led to a policy discourse that intertwines social exclusion, area-based initiatives, liveability, restructuring, integration, manageability and social mixing (see Uitermark 2003). This eclectic discourse, which to some extent connects to Western European urban policies in general, has unmistakably affected the Programme's design. In addition, the Programme is a continuation of previous policies that were designed to stimulate physical restructuring in several neighbourhoods. Hence, it inherited a legacy that was focused on physical restructuring rather than on social-economic deprivation and exclusion (Musterd and Ostendorf 2008).

Secondly, the history of restructuring policies also created the institutional embeddedness of the Programme. As mentioned, the Programme is the responsibility of the Ministry of Housing and Spatial Planning, which together with municipalities and housing associations formed the triumvirate of Dutch urban renewal policies for 35 years (Schuiling 2007). However, we can only speculate that the involvement of housing associations may be reflected in the use of a social-rented housing indicator in the selection. Nevertheless, it appears that, despite the emphasis on social division, the Programme and its actors are very much affected by the Dutch tradition of physical restructuring and urban renewal.

Lastly, the Programme connects to Western European policy trends as it focuses on issues of social exclusion and integration on the neighbourhood level and less on social inequalities. This seems to reflect the change in social welfare priorities since the rise of neo-liberalism in the 1980s.

However, the observation that any policy is irrevocably affected by its history, by political arguments and institutional embeddedness does not mean that we should cease to strive for interventions that effectively alter social mechanisms and produce sound indicators based on social scientific insight. As Andrew Sayer argues:

If social scientific accounts differ from those of actors then they cannot help but be critical of lay thought and action. Furthermore, (...) to identify understandings in society as false (...) is to imply that (...) those beliefs and actions ought to be changed. (Sayer 2000, p. 19)

In case of the 40 neighbourhoods programme, policymakers should separate the objectives and choose one to focus on. This will increase efficiency and the chances of successfully tackling the city's 'wicked' problems.

When liveability issues are the most urgent problems, the Programme will have to improve its indicators and indexation methods. Furthermore, policymakers will have to accept that serious liveability issues do not necessarily appear in neighbourhoods with social deprivation or a high share of social housing.

Alternatively, when social exclusion and deprivation are the dominant issue at hand, the Programme should be overhauled. Socio-economic deprivation is a phenomenon at the individual level, and, as we have seen, poor individuals are too scattered in The Netherlands to warrant an area-based approach.

To conclude, we want to stress that policymakers should invest more in social theory and research when it comes to planning strategies that seek to alter social mechanisms. 
Acknowledgments The authors would like to thank Brooke Sykes and everyone who provided comments on earlier drafts. This research was co-funded by the Corpovenista/Habiforum Research Programme.

Open Access This article is distributed under the terms of the Creative Commons Attribution Noncommercial License which permits any noncommercial use, distribution, and reproduction in any medium, provided the original author(s) and source are credited.

\section{References}

Andersen, H. S. (2003). Urban sores: On the interaction between segregation, urban decay and deprived neighbourhoods. Aldershot: Ashgate.

Andersson, R., \& Musterd, S. (2005). Area-based policies: A critical appraisal. Tijdschrift voor Economische en Sociale Geografie, 96, 377-389.

Atkinson, R. (2000). Combating social exclusion in Europe: The new urban policy challenge. Urban Studies, 37, 1037-1055.

Atkinson, T., Cantillon, B., Marlier, E., \& Nolan, B. (2002). Social indicators: The EU and social inclusion. Oxford: Oxford University Press.

Belmessous, F., Chignier-Riboulon, F., Commerçon, N., \& Zepf, M. (2005). Demolition of large housing estates: An overview. In R.v. Kempen, K. Dekker, S. Hall, \& I. Tosics (Eds.), Restructuring large housing estates in Europe (pp. 193-210). Bristol: The Policy Press.

Boelhouwer, P. (2007). The future of Dutch housing associations. Journal of Housing and the Built Environment, 22, 383-391.

Cole, I., \& Etherington, D. (2005). Neighbourhood renewal policy and spatial differentiation in housing markets: Recent trends in England and Denmark. European Journal of Housing Policy, 5, 77-97.

Davoudi, S. (2006). Evidence-based planning; Rhetoric and reality. disP, 165, 14-24.

De Decker, P., Vranken, J., Beaumont, J., \& Nieuwenhuyze, I. v. (Eds.). (2003). On the origins of urban development programmes in nine European countries. Antwerpen/Apeldoorn: Garant.

Forrest, R., \& Murie, A. (1990). Selling the welfare state (2nd ed.). London: Routledge.

Galster, G. (2007). Should policy makers strive for neighborhood social mix? An analysis of the western European evidence base. Housing Studies, 22, 523-545.

Goetz, E. G. (2003). Clearing the way. Washington, DC: The Urban Institute.

Lawless, P. (2007). New deal for communities in England: Is area based regeneration possible?. Lisbon: Paper presented at Regional Studies Association International Conference.

Musterd, S. (2005). Social and ethnic segregation in Europe; levels, causes and effects. Journal of Urban Affairs, 27, 331-348.

Musterd, S., \& Ostendorf, W. (2007). Spatial segregation and integration in The Netherlands. In K. Schönwälder (Ed.), Residential segregation and the integration of immigrants: Britain, The Netherlands, Sweden (pp. 41-60). Berlin: Social Science Research Center WZB.

Musterd, S., \& Ostendorf, W. (2008). Integrated urban renewal in The Netherlands, a critical appraisal. Urban Research \& Practice, 1, 1-15.

Parkes, A., Kearns, A., \& Atkinson, R. (2002). What makes people dissatisfied with their neighbourhoods? Urban Studies, 39, 2413-2438.

Parsons, W. (2002). From muddling through to muddling up-evidence based policy making and the modernisation of British government. Public Policy and Administration, 17, 43-60.

Pawson, R., \& Tilley, N. (1997). Realistic evaluation. London: Sage.

Pinkster, F. (2006). Inkomenssegregatie in Nederlandse Steden. In C. H. Mulder \& F. Pinkster (Eds.), Onderscheid in wonen; het sociale van binnen en buiten (pp. 99-122). Amsterdam: Amsterdam University Press.

Rhodes, J., Tyler, P., \& Brennan, A. (2005). Assessing the effect of area based initiatives on local area outcomes: Some thoughts based on the national evaluation of the single regeneration budget in England. Urban Studies, 42, 1919-1946.

Sanderson, I. (2002). Evaluation, policy learning and evidence-based policy making. Public Administration, $80,1-22$.

Sayer, A. (2000). Realism and social science. London: Sage.

Schuiling, D. (2007). Stadsvernieuwing door de jaren heen (Urban renewal through the years). Rooilijn, 40, $159-165$.

Solesbury, W. (2002). The ascendancy of evidence. Planning Theory and Practice, 3, 90-96. 
Tsakloglou, P., \& Papadopoulos, F. (2002). Aggregate level and determining factors of social exclusion in twelve European countries. Journal of European Social Policy, 12, 211-225.

Uitermark, J. (2003). 'Social mixing' and the management of disadvantaged neighbourhoods: The Dutch policy of urban restructuring. Urban Studies, 40, 531-549.

Van der Schaar, J. (2006). Wonen en woonbeleid; markten, beleid, instrumenten. Amsterdam: Universiteit van Amsterdam, Faculteit der Maatschappij en Gedragswetenschappen.

Van Gent, W., Musterd, S, \& Ostendorf, W. (2007). Van Probleemwijk Naar Prachtwijk? Tijdschrift voor de Volkshuisvesting, 13, 44-50.

Van Kempen, R., \& Priemus, H. (2002). Revolution in social housing in The Netherlands: Possible effects of new housing policies. Urban Studies, 39, 237-253.

Vogelaar, E. (2008). Wijkaanpak is veel meer dan slopen en bouwen. de Volkskrant, 11. 